DOI: $10.17058 /$ rjp.v5i2.5802

\title{
UMA ANÁLISE DAS MUDANÇAS NAS DINÂMICAS ASSOCIATIVAS DE DUAS ORGANIZAÇÕES DA ÁREA DA ASSISTÊNCIA NA REGIÃO DO VALE DO RIO PARDO
}

\author{
Millena Rodrigues Hermes ${ }^{1}$ \\ Cláudia Tirelli ${ }^{2}$
}

\begin{abstract}
RESUMO
O artigo analisa de que forma a reconfiguração do campo da assistência, observada no Brasil a partir do final dos anos de 1980 e ao longo da década de 1990, vem alterando as dinâmicas associativas das organizações da sociedade civil em termos dos seus repertórios organizacionais e de ação, da adoção de novos marcos interpretativos e do acesso a recursos financeiros. A investigação empírica da pesquisa foi realizada por meio de dois estudos de caso em organizações sociais com trajetórias institucionais distintas, mas que participaram do programa Rede Parceria Social na Região do Vale do Rio Pardo no mesmo período (20082013). Como resultado, a pesquisa aponta que as oportunidades políticas são apropriadas de forma diversa pelos atores associativos, de acordo com as suas trajetórias institucionais e a sua posição no campo da assistência, contestando as teses que apontam para um processo amplo de colonização dos atores da sociedade civil pelo mercado ou de sua hegemonização por um projeto político neoliberal.
\end{abstract}

Palavras-chave: Reconfiguração da assistência. Dinâmicas associativas. Sociedade civil.

\begin{abstract}
This paper analyses in which way the reconfiguration of the assistance field, as seen in Brazil from the end of the 1980s decade and during the entire 1990s, has been changing associative dynamics in organizations belonging to the civil society in terms of their actions and organizational repertoires, adoption of new interpretative frameworks and access to financial resources. The research's empirical investigation was performed by means of two case studies in social organizations following different institutional paths, but participating Rede Parceria Social program at the same time in Vale do Rio Pardo`s Region (2008-2013). As a result, the research indicates that political opportunities have been appropriated, in different ways, by associative actors, according to their institutional paths and position in the assistance field, contesting the thesis which point to a wide colonization process of the actors from the civil society by the market or their hegemonization by a neoliberal political project.
\end{abstract}

Keywords: Reconfiguration of assistance. Associative dynamics. Civil Society.

\footnotetext{
1 Aluna do Curso de Psicologia da Universidade de Santa Cruz do Sul - UNISC.

<millena_hermes@hotmail.com>

2 Professora do Departamento de Ciências Humanas na Universidade de Santa Cruz do Sul - UNISC.

<ctirelli@unisc.br>
} 
DOI: $10.17058 /$ rjp.v5i2.5802

\section{INTRODUÇÃO}

Desde os anos de 1990, pode-se observar, no Brasil, diversas mudanças nas dinâmicas associativas das organizações civis, tanto no que se refere às suas formas de organização e gestão, como em relação aos seus repertórios de atuação, quadros interpretativos e origens dos seus recursos financeiros. Nesse sentido, salienta-se, principalmente, a crescente profissionalização dessas organizações, a adoção de modelos de planejamento institucional e a execução das ações via elaboração de projetos sociais. As formas de sustentabilidade das organizações também se alteraram, fazendo com que muitas dessas organizações civis, que antes recebiam recursos provenientes de agências e Organizações Não Governamentais (ONGs) internacionais, passassem a assegurar a sua manutenção financeira por meio da prestação de serviços para o Estado através da implementação de políticas públicas. As análises dos cientistas sociais a respeito desse amplo processo de mudanças têm oscilado, em grandes linhas, entre trabalhos que apontam para processos generalizados de "colonização" do espaço social pelos atores e metodologias do mercado (MÜLLER, 2006) e aqueles que o atribuem à "hegemonização" dessas organizações por um macroprojeto político neoliberal (DAGNINO, OLVERA e PANFICHI, 2006; TATAGIBA, 2006; ALMEIDA, 2006).

O objetivo deste artigo é trazer novos elementos empíricos que possibilitem pensar sobre como as trajetórias institucionais das organizações civis influenciam na forma como estas se comportam frente as oportunidades e restrições políticas presentes em cada conjuntura. No caso particular desta pesquisa, investigamos como se deu essa apropriação, por parte de duas organizações da área da assistência que atuam na Região do Vale do Rio Pardo (RVRP), em relação a um Programa desenvolvido pelo Governo do Estado do RS Programa Rede Parceria Social - entre 2008 e 2013. A partir da realização desses dois estudos de caso na RVRP, busca-se ampliar o escopo empírico de uma pesquisa anterior (TIRELLI, 2013), desenvolvida com organizações sociais da Região Metropolitana de Porto Alegre, na qual se almejava resgatar as condições de possibilidade de agência desses atores sociais no campo da assistência, mesmo que considerada uma agência relativa, através da adoção de uma perspectiva teórico-metodológica que os percebesse como posicionados dentro de um espaço relacional que restringe as suas ações a um campo limitado de possíveis.

$\mathrm{O}$ artigo encontra-se dividido em quatro seções: na primeira, descreve-se a conjuntura crítica que emergiu no Brasil no fim dos anos de 1980 e ao longo dos anos de 1990, a qual possibilitou uma reconfiguração da área da assistência social no país; na 
DOI: $10.17058 /$ rjp.v5i2.5802

segunda, analisa-se o Programa Rede Parceria Social enquanto uma nova oportunidade política que se coloca para os atores no campo da assistência; na terceira seção, expõe-se a metodologia e os procedimentos de pesquisa utilizados e, por fim, na quarta e última seção, apresentam-se os resultados parciais de nossa investigação, os quais foram produzidos com base no histórico institucional das duas organizações, que demonstraram a diversidade de apropriações das oportunidades políticas existentes.

\section{UMA BREVE CONTEXTUALIZAÇÃO: A “CONJUNTURA CRÍTICA” DOS ANOS DE 1990 E A RECONFIGURAÇÃO DA ASSISTÊNCIA}

A partir do final dos anos 1980 e ao longo da década de 1990, assistiu-se a uma ampla reconfiguração do campo da assistência social no Brasil, resultante de múltiplos processos, atores e intencionalidades. Esta reconfiguração resultou do surgimento, naquela conjuntura, de novas oportunidades e constrangimentos para os atores sociais ("novos e velhos") que atuavam no campo da assistência, os quais se apropriaram distintamente dessas oportunidades, de acordo com as suas trajetórias institucionais. (TIRELLI, 2013)

Esses momentos de "rápida" mudança, nos quais se verifica a emergência de novas oportunidades e restrições políticas aos atores de um determinado campo, na medida em que são precedidos por longos períodos de continuidade e reprodução institucional, são chamados de "conjunturas críticas", conforme a abordagem do Institucionalismo Histórico (PIERSON e SKOCPOL, 2008). Segundo Capoccia e Kelemen (2007), as análises desenvolvidas por grande parte dos institucionalistas históricos partem de um modelo dual, no qual se alternam processos longos de estabilidade e de reprodução institucional e momentos relativamente curtos de quebra dessa estabilidade, nas quais há um relaxamento nos aspectos estruturais que condicionam as ações dos atores em tempos normais, possibilitando a abertura de novos processos e escolhas para estes.

Já as oportunidades e restrições políticas, conforme McAdam, Tarrow e Tilly (2009), dizem respeito às organizações formais de governo e de políticas públicas, à facilitação ou repressão por parte das autoridades e a presença de aliados potenciais, rivais ou inimigos. Quando ocorrem mudanças em algum desses elementos, alteram-se as condições que encorajam ou, por outro lado, constrangem as ações coletivas de confronto. No caso desta pesquisa, não se trata de analisar ações coletivas de confronto, mas de ver como esses 
DOI: $10.17058 /$ rjp.v5i2.5802

elementos externos às organizações assistenciais, além da posição que ocupam dentro do campo, condicionam as suas possibilidades de interpretação e atuação.

Com base em uma pesquisa anterior sobre esta mesma problemática (TIRELLI, 2013), identificou-se que, dentre os processos que propiciaram a emergência da conjuntura crítica no campo da assistência no Brasil, ao longo dos anos de 1990, podem ser destacados os seguintes:

\subsection{As mudanças na legislação}

Na década de 1990, houve a aprovação de diversas leis que atingiram os atores da área da assistência, como, por exemplo, o Estatuto da Criança e do Adolescente (ECA), aprovado em 1990, e a Lei Orgânica da Assistência Social (LOAS), em 1993. Nesse período também foram criadas a Lei das Organizações da Sociedade Civil de Interesse Público (OSCIPs), em 1999, e a Lei das Organizações Sociais (OS), em 1998. Essas novas legislações vão afetar as organizações sociais que atuam no campo da assistência, pois, por um lado, vão disciplinar a condução do trabalho social e a distribuição dos seus recursos, exigindo um maior planejamento e profissionalização das atividades desenvolvidas e; por outro, vão abrir novos espaços para a contratualização de organizações da sociedade civil para a execução de programas e projetos vinculados às políticas públicas setoriais ou, em alguns casos, para o desenvolvimento de projetos desenvolvidos paralelamente a essas políticas.

\subsection{A ampliação dos espaços de participação institucional para as organizações da sociedade civil}

A partir da redemocratização do país e da promulgação da Constituição de 1988, vários espaços foram abertos à participação das organizações da sociedade civil, entre esses, podem ser citados os Orçamentos Participativos (OPs), os conselhos gestores de políticas, os conselhos de direitos, os fóruns, as conferências públicas, etc.. Esta participação vai exigir uma maior especialização e profissionalização dos quadros das organizações sociais, sobretudo daquelas que não estavam habituadas a trabalhar com base em procedimentos de planejamento e de gestão. A interlocução do Estado com a sociedade passa a se dar, nesse período, através da mediação das organizações da sociedade civil que se reconhecem e são reconhecidas nesses espaços, como representantes de determinados segmentos ou causas sociais. 
DOI: $10.17058 /$ rjp.v5i2.5802

\subsection{A entrada de novos atores associativos no campo da assistência}

Observa-se, também, a entrada de novos atores associativos no campo da assistência (ONGs, fundações e institutos empresariais, empresas, organismos de cooperação internacional), os quais irão se somar às organizações tradicionais vinculadas a esse espaço, ou seja, às organizações/entidades caritativas e às instituições assistenciais do Estado.

\subsubsection{As Organizações Não Governamentais (ONGs)}

Apesar de uma parcela das chamadas ONGs não se identificarem como vinculadas ao campo da assistência, seu campo de atuação apresenta-se, desde o início, muito imbricado com o campo da assistência e, nos últimos anos, esse processo tem recrudescido, na medida em que as ONGs de defesa de direitos estão também prestando serviços ao Estado. Os anos 1990 também vão representar um período de expressivo crescimento do número de organizações sociais no Brasil, sobretudo das identificadas como Organizações Não Governamentais (ONGs) voltadas à defesa de direitos. A pesquisa FASFIL 2010, realizada pelo IBGE, IPEA, GIFE e ABONG (2012), revela um expressivo crescimento no número de organizações de defesa de direitos durante a década de 90 , quando representavam $31 \%$ do total de organizações sem fins lucrativos existentes no Brasil e, de forma ainda mais acentuada, durante a primeira década do século XXI, quando passam a representar $40,8 \%$ do total. A criação dessas inúmeras organizações voltadas à defesa de direitos de públicos e causas específicas pode ser explicada pelas oportunidades políticas abertas pelo Estado brasileiro e pelos organismos de cooperação multilaterais e bilaterais, que elegem as ONGs como parceiras ideais para o desenvolvimento de seus projetos sociais no Brasil. Esses organismos desempenharam um papel crucial para alavancar e legitimar um novo modelo de trabalho social no Brasil e em outros países periféricos.

\subsubsection{Os empresários}

De acordo com Paula e Rodhen (1998), os anos 1990 apresentaram uma mudança significativa nas ações de responsabilidade social promovidas por empresários no Brasil, pois essas deixaram de se constituir enquanto iniciativas isoladas de alguns empresários benfeitores para tornarem-se estratégias das empresas previstas no seu planejamento orçamentário e na sua estrutura organizacional. Nesse sentido, foram criadas nesse período 
DOI: $10.17058 /$ rjp.v5i2.5802

organizações de representação empresarial (GIFE e Instituto Ethos) voltadas ao incentivo e disseminação de práticas de responsabilidade social empresarial e da adoção de um comportamento ético por parte das empresas.

\subsection{As mudanças operadas nas entidades/organizações de assistência}

As organizações/entidades de assistência também realizaram várias modificações nos seus padrões de organização e de atuação durante os anos 1990. A abertura de novas oportunidades políticas ampliou as possibilidades de obtenção de recursos financeiros para essas organizações na área da assistência, tanto pela via do Estado como através de instituições privadas (empresas e fundações e institutos empresariais). Os financiadores passaram a exigir uma maior profissionalização das suas ações, através da utilização de metodologias de planejamento e de gestão (de projetos e institucional). Particularmente em relação às organizações da área da assistência, pode-se perceber que o discurso dos seus dirigentes tende a enfatizar, de forma recorrente, o rompimento com uma visão assistencialista adotada anteriormente em relação aos pobres e a adoção de uma perspectiva de garantia de direitos de grupos vulnerabilizados, conforme o previsto pela Constituição de 1988.

\section{O PROCESSO DE FORMULAÇÃO E OS PRESSUPOSTOS DO PROGRAMA REDE PARCERIA SOCIAL}

O Programa Rede Parceria Social (PRPS) foi lançado em 2007, durante a gestão de Yeda Crusius (PSDB) no Governo do Estado do Rio Grande do Sul (RS). O programa visava implantar um novo modelo de planejamento e gestão do trabalho assistencial, nos moldes do que havia sido feito através da Lei Roaunet na área da cultura. A ideia principal era viabilizar as ações da assistência através do aporte de recursos financeiros provenientes de doações de empresas (via renúncia fiscal) e da implementação das ações assistenciais por meio de organizações/entidades não-estatais.

Conforme descrito na Revista Rede Parcerias Sociais, os pressupostos do programa vão reunir os 
DOI: $10.17058 /$ rjp.v5i2.5802

[...] aspectos fundamentais desse novo tipo de relação que se estabelece entre Governos, Empresas e Organizações Sociais. As palavras-chave são Parceria (entre esferas de governo, entre governo, empresas e ONGs, universidades, pessoas); Solidariedade, como o reconhecimento humano e ético das necessidades das populações menos favorecidas; Descentralização das ações, para atingir a todos, com mais eficiência e eficácia, Formação de Capital Social, incentivando a capacidade associativa, a consciência cívica, os valores éticos e o grau de confiança dos cidadãos, Formação de Capital Humano, qualificando os atuais agentes e formando novos atores para atuar no desenvolvimento de organizações e do Estado como um todo. $(2009$, p. 7$)$

Pode-se perceber, claramente, que o PRPS foi estruturado sobre a perspectiva do estabelecimento de parcerias público-privadas para o desenvolvimento de projetos na área da assistência, envolvendo as organizações da sociedade civil e os atores empresariais em várias fases do processo, desde o planejamento e a elaboração dos projetos, passando pelo financiamento, acompanhamento e avaliação das ações desenvolvidas.

Conforme Tirelli (2013), o PRPS foi pensado como uma forma de fazer frente a uma concepção estatista da Assistência baseada no financiamento, gestão e provisão dos serviços através de órgãos e instituições do Estado. Os formuladores do PRPS eram muito críticos a essa concepção estatista, pois a consideravam excessivamente burocratizada, centralizada, ineficaz e dominada por interesses corporativos dos funcionários públicos. Nesse sentido, toda a formulação e implementação do Programa visava estruturar um modelo alternativo ao modelo estatal, considerado mais eficaz e republicano do que o último.

Em razão desses aspectos é que se elegeu este Programa como o delimitador empírico das organizações pesquisadas, pois, assim, poder-se-ia analisar de que forma elas se comportam ao estabelecerem relações com o PRPS e o modelo gerencial que ele encampa. Ou seja, o PRPS representa uma nova oportunidade política para as organizações da assistência, as quais poderão se apropriar de diferentes formas dessa oportunidade, como demonstramos nos nossos estudos de caso.

\section{A METOdOLOGIA DE PESQUISA: OS ESTUdOS DE CASO MÚLTIPLOS}

Na medida em que se busca problematizar teoricamente a interferência da trajetória institucional dos atores sociais sobre a forma como se apropriam e agem frente as oportunidades e ameaças políticas em determinadas conjunturas, nos pareceu importante selecionar organizações que apresentassem ecologias organizacionais e trajetórias distintas desde a sua criação até o presente. Desta forma, optou-se pela realização de estudos de caso múltiplos, pois eles permitem levantar mais evidências que contradigam os argumentos mais 
DOI: $10.17058 /$ rjp.v5i2.5802

gerais que a literatura brasileira tem utilizado para explicar os processos de mudança nas organizações sociais.

Conforme Yin (2001), os casos não constituem unidades de amostragem aleatória de certas populações ou de um universo de pesquisa e nem foram escolhidos a partir desse critério de representatividade. A utilização de estudos de casos múltiplos deve seguir uma lógica de replicação, e não de amostragem.

Esta característica específica dos estudos de caso não impede que se façam generalizações a partir deles, mas Yin adverte que essas generalizações não se baseiam em cálculos estatísticos e que o "[seu] método de generalização é a generalização analítica, no qual se utiliza uma teoria previamente desenvolvida como modelo com o qual se deve comparar os resultados empíricos do estudo de caso.” (YIN, 2001, p. 54). Em relação à nossa pesquisa, os casos servem para problematizar os argumentos dominantes apresentados pelas perspectivas teóricas que apontam para processos amplos de colonização e de hegemonização das organizações sociais pelos atores e metodologias do mercado e/ou do Estado ou por um macroprojeto político neoliberal e, ao mesmo tempo, demonstrar a pertinência de se utilizar um aporte teórico alternativo.

Para a coleta dos dados, utilizaram-se diferentes técnicas e procedimentos de investigação. Em primeiro lugar, realizou-se uma pesquisa documental junto aos materiais disponibilizados em sites pelo Governo Estadual com relação ao PRPS. A partir da análise deste material é que foram selecionados os dois casos na RVRP, o Lar Esperança Mary Taranger e a Sociedade Cultural e Beneficente União.

Cada caso envolveu procedimentos de coleta diferenciados, pois as informações disponíveis eram de caráter distinto e proveniente de fontes variadas. No caso do Lar Esperança Mary Taranger, realizou-se uma entrevista semiestruturada com a coordenadora atual e analisaram-se documentos e materiais de divulgação da organização. No caso da Sociedade Cultural e Beneficente União, utilizou-se como fontes um documentário produzido por pesquisadores da UNISC sobre a organização, no qual aparecem entrevistas com alguns de seus integrantes e lideranças, e materiais produzidos para apresentações em congressos. As informações sobre a Sociedade Cultural e Beneficente União serão complementadas, posteriormente, com a realização de entrevistas com as lideranças das últimas gestões da entidade.

A partir das informações construídas com base nesse conjunto de materiais, pôde-se reconstruir, parcialmente, a trajetória dessas organizações, o que nos auxilia na compreensão 
DOI: $10.17058 /$ rjp.v5i2.5802

acerca da forma como elas se apropriam de oportunidades políticas como as representadas pelo PRPS.

\section{OS CASOS ESTUDADOS: O RESGATE DA TRAJETÓRIA INSTITUCIONAL DAS DUAS ORGANIZAÇÕES}

\subsection{O Lar Esperança Mary Taranger}

O Lar Esperança Mary Taranger foi fundado em 1968 no município de Rio Pardo/RS. Foi criado por adeptos da Igreja Assembleia de Deus com o objetivo de abrigar e educar crianças e adolescentes (0-21 anos) em situação de vulnerabilidade social. Segundo o relato da atual coordenadora, um grupo de adeptos da Igreja Assembleia de Deus, com recursos provenientes da Suécia, formou naquele ano uma rede de orfanatos chamada Rede Esperança, a qual atendia crianças e jovens de vários municípios do RS. Até os anos 1990, os orfanatos eram dirigidos pelos pastores da Igreja, o que, segundo a entrevistada, trouxe alguns problemas em relação ao uso dos recursos financeiros doados da Suécia e a prestação de contas. Havia, também, a exigência de que as crianças e jovens abrigados tivessem uma formação doutrinária dentro dos preceitos dessa igreja.

A partir do início da década de 1990, a instituição de Rio Pardo começa a se adequar às exigências da nova Política de Assistência Social. De acordo com a entrevistada, o pastor que assumiu a presidência da instituição, em 1992, possuía um perfil inovador e buscou inserir a instituição dentro da nova legislação. Nesse sentido, inscreveu o Orfanato no Conselho Municipal de Assistência e, mais tarde, em 1997, propôs a criação de um regimento específico da instituição, já que o existente dizia respeito somente à igreja. A partir daí, foi criado um estatuto de acordo com o código civil e houve a desvinculação da Igreja Assembleia de Deus. No entanto, de acordo com o seu relato, a filosofia da instituição ainda é uma filosofia evangélica, mas sem nenhuma vinculação com igrejas. Também em 1997, começaram a ser buscados recursos de outras fontes, além daqueles provenientes da Suécia, pois os coordenadores da instituição perceberam que não receberiam essas doações para sempre, já que o molde do trabalho assistencial executado naquele país ia em um sentido contrário ao previsto na legislação brasileira. Segundo o exemplo dado pela atual coordenadora, no Brasil a ideia de abrigo é vista como temporária, ou seja, existe um trabalho voltado à adoção das crianças e jovens abrigados ou, caso seja viável, o retorno dessas para 
DOI: $10.17058 /$ rjp.v5i2.5802

suas famílias. A seu ver, na Suécia, o processo de abrigagem era mais condizente com a ideia restrita de orfanato, no qual as crianças cortariam os vínculos familiares.

Com relação à sustentabilidade financeira da instituição, as mudanças ocorreram em 2006, quando os doadores da Suécia suspenderam o repasse de recursos. Atualmente, a instituição tem a sua manutenção garantida através de recursos provenientes da Prefeitura Municipal de Rio Pardo, da Prefeitura Municipal de Pântano Grande e da União. De acordo com a coordenadora atual, o fato da instituição ser vista como ligada à Igreja Assembleia de Deus, repercute negativamente no montante de doações recebidas de pessoas físicas, pois a população de Rio Pardo é preponderantemente católica.

Segundo a entrevistada, a participação da instituição no PRPS teve a intenção de obter um adicional a um projeto que já estava em andamento. O objetivo era captar mais recursos, pois a estrutura financeira para o básico eles já tinham. A seu ver, como as doações da Suécia cessaram, o PRPS supriu algumas lacunas. Salienta, também, que na época que venceram o edital para a execução de projetos via PRPS tiveram que fazer uma capacitação com a ONG Parceiros Voluntários sobre "como elaborar projetos". Alguns projetos encaminhados pela instituição em outros editais do PRPS não foram aprovados, pois nem sempre a instituição contempla o perfil exigido nas propostas.

Atualmente, o abrigo passou a ser uma Instituição de Acolhimento. A diretoria é toda formada por voluntários e as cuidadoras são contratadas e possuem carteira assinada. Recentemente, foram contratadas uma psicóloga e uma assistente social para o quadro de profissionais da instituição. Pode-se perceber, portanto, que a organização vem incrementando a profissionalização no atendimento às crianças e jovens.

\subsection{A Sociedade Cultural e Beneficente União}

A Sociedade Cultural e Beneficente União foi criada em 1923, no município de Santa Cruz do Sul/RS, por um grupo de pessoas preocupadas em criar um espaço esportivo e recreativo para a valorização da cultura afro-brasileira no município. Inicialmente, a organização restringia-se a um time de futebol mas, com o passar do tempo, transformou-se em um clube com finalidades mais amplas. Define-se como uma entidade sem fins lucrativos que tem como objetivo divulgar e preservar a cultura afro-brasileira em Santa Cruz do Sul. A organização foi criada para propiciar um espaço no qual a população negra pudesse conviver e vivenciar suas tradições culturais. Segundo o depoimento de um ex-dirigente da organização, quando foi doado o terreno para a sua construção, este se localizava num local 
DOI: $10.17058 /$ rjp.v5i2.5802

da periferia da cidade. Com o processo de urbanização, o local da organização hoje é considerado bem próximo à área central da cidade.

No final dos anos de 1960, a organização foi registrada em Brasília e precisou alterar a sua denominação. Segundo o dirigente entrevistado no vídeo, até aquele período pessoas brancas não entravam na organização. A partir dessa época, isto se alterou e o clube se abriu para o pessoal do centro, promovendo sambões abertos ao público em geral. No caso de outros bailes no centro da cidade, o clube ia como convidado e só entrava quem eles indicassem, neste caso, só entravam junto com a escola de samba que era a convidada. De acordo com o seu relato, nos outros clubes da cidade, na época e ainda hoje, a diretoria avalia se aceita ou não o novo sócio. Esta postura, na visão do entrevistado, representa um preconceito "mascarado". Por fim, ele reitera que o clube foi criado para as pessoas negras terem um lugar para se encontrar, pois o negro não tinha espaço na cidade.

$\mathrm{Na}$ fala de um dos dirigentes entrevistados no vídeo, o clube visa também dar visibilidade às pessoas negras que moram no município. Segundo ele, o carnaval seria um dos meios de se fazer isso, embora saliente que estão faltando mais momentos de visibilidades.

Segundo o relato de um ex-presidente da organização, entre 1999 e 2005, ela entrou em decadência e chegou a ser fechada. Segundo ele, os presidentes não se preocupavam e havia apenas 9 sócios pagantes. Quando ele assumiu, em 2005, foi necessário recomeçar todo o trabalho. Precisou reunir documentos para registrar a Sociedade União na receita federal, no estado e até no município.

Além da parte esportiva, a organização promove várias festas, como bailes, sambões, festa para mulheres, além de se envolver com todos os preparativos para o desfile de carnaval. A organização também desenvolve projetos sociais com crianças e conseguiu, recentemente, acessar alguns recursos para projetos específicos via editais. Os recursos provenientes do PRPS, por exemplo, possibilitaram diversas melhorias na infraestrutura da organização, pois o prédio vinha se deteriorando em virtude do desgaste do tempo aliado à falta de manutenção.

\section{CONSIDERAÇÕES FINAIS}

A partir da recuperação parcial da trajetória institucional desses dois casos na Região do Vale do Rio Pardo, buscou-se perceber como as organizações sociais vão responder diferentemente às oportunidades e restrições políticas com as quais se defrontam. Portanto, a posição que as organizações ocupam em um dado campo de atuação, a qual resulta da sua 
DOI: $10.17058 /$ rjp.v5i2.5802

história pregressa neste campo, condiciona as suas relações e possibilidades de intervenção nesse espaço social.

Embora se possa identificar algumas tendências dentro do campo de atuação das organizações civis, como é o caso da realização das ações através de "projetos sociais" e a profissionalização crescente do trabalho social em boa parte das organizações, também é verdade que essas organizações não respondem uniformemente às novas oportunidades políticas, podendo-se perceber algumas que adotam uma postura de completa adesão ao marco gerencial, enquanto outras realizam uma espécie de "adaptação pragmática" desse mesmo marco, participando dos editais e se adequando às suas exigências sem abrir mão dos seus pressupostos institucionais e ideológicos, e há, ainda, aquelas que preferem fechar as portas do que sobreviver dessa forma.

\section{REFERÊNCIAS}

ALMEIDA, C. O marco discursivo da "Participação Solidária" e a nova agenda de formulação e implementação de ações sociais no Brasil. In: DAGNINO, E.; OLVERA, A.; PANFICHI, A. (Orgs.). A disputa pela construção democrática na América Latina. São Paulo: Paz e Terra, 2006. p. 95-135.

AZEREDO, I. J. (Coord.). Introdução ao resgate cultural, valorização e fortalecimento das agremiações vinculadas à comunidade negra no vale do Rio Pardo. Santa Cruz do Sul: UNISC TV, 2008. 4 v. DVDS (ca. 116 min): NTSC: son., color. + 5 CD-ROMS.

CAPOCCIA, G.; KELEMEN, R. D. The study of critical junctures: theory, narrative, and counterfactuals in historical Institutionalism. World Politics, Cambridge, n. 3, v. 59, p. 341369, abr. 2007. Disponível em: http://journals. cambridge. org/action/displayAbstract?fromPage $=$ online $\&$ aid $=7693564 \&$ fileId $=$ S0043887100 020852. Acesso em: jul. 2015.

DAGNINO, E.; OLVERA, A.; PANFICHI, A. Para uma outra leitura da disputa pela construção democrática na América Latina. In: DAGNINO, E.; OLVERA, A.; PANFICHI, A. (Orgs.). A disputa pela construção democrática na América Latina. São Paulo: Paz e Terra, 2006, p. 13-91.

IBGE, IPEA, GIFE, ABONG. As Fundações Privadas e Associações sem Fins Lucrativos no Brasil-2010. Rio de Janeiro: IBGE, 2012. Disponível em: http://www.ibge.gov.br/ home/estatistica/economia/fasfil/2010/. Acesso em: jul. 2015.

McADAM, D.; TARROW, S.; TILLY, C. Para mapear o confronto político. Lua Nova, São Paulo, n. 76, p. 11-48, 2009. 
DOI: $10.17058 /$ rjp.v5i2.5802

MÜLLER, L H. A. A construção do social a partir da ótica empresarial. In: V WORKSHOP EMPRESA, EMPRESÁRIOS E SOCIEDADE. Porto Alegre: PUCRS, 2006. 1 CD-ROM.

PAULA, S. G.; ROHDEN, F. Filantropia empresarial em discussão: números e concepções a partir do estudo do Prêmio Eco. In: LANDIM, L. (Org.). Ações em sociedade: militância, caridade, assistência etc. Rio de Janeiro: NAU, 1998.

PIERSON, P. e SKOCPOL, T. El Institucionalismo Histórico en la Ciencia Política Contemporánea. Revista Uruguaya de Ciencia Política, Montevideo, n. 1, v. 17, p.07-38, 2008 .

REVISTA REDE PARCERIAS SOCIAIS. Porto Alegre: Secretaria da Justiça e do Desenvolvimento Social do RS, jul. 2009.

TATAGIBA, L. Os desafios da articulação entre Sociedade Civil e Sociedade Política sob o marco da democracia gerencia: $O$ caso do Projeto Rede Criança em Vitória/ES. In: DAGNINO, E.; OLVERA, A.; PANFICHI, A. (Orgs.). A disputa pela construção democrática na América Latina. São Paulo: Paz e Terra, 2006. p. 137-178.

TIRELLI, C. Reconfiguração da Assistência e Organizações Sociais no RS: um estudo das organizações que participaram do Programa Rede Parceria Social entre 2008 e 2010. Porto Alegre, 2013. 236 p. Tese (Doutorado), Programa de Pós-Graduação em Sociologia, Universidade Federal do Rio Grande do Sul, 2013.

YIN, R. K. Estudo de caso: planejamento e métodos. 2. ed. Porto Alegre: Bookman, 2001. 